\title{
A comparison of the bone density and morphology of giraffe (Giraffa camelopardalis) and buffalo (Syncerus caffer) skeletons
}

\author{
O. L. van Schalkwyk ${ }^{1 *}$, J. D. Skinner ${ }^{1}$ and G. Mitchell ${ }^{1,2}$ \\ ${ }^{1}$ Veterinary Wildlife Unit, Faculty of Veterinary Science, Private Bag X04, University of Pretoria, Onderstepoort 0110, South Africa \\ ${ }^{2}$ Department of Zoology and Physiology, University of Wyoming, Laramie, WY 82071, U.S.A. \\ (Accepted 13 April 2004)
}

\begin{abstract}
Unique features of giraffe Giraffa camelopardalis anatomy are its long neck and slender long limbs. Its neck vertebrae should be light and have low density to make it manoeuvrable while the limb bones should have high density to provide the strength to support the giraffe's mass. Giraffes also have a very high vertical growth rate, a diet with a high $\mathrm{Ca}: \mathrm{P}$ ratio, and a skeleton that constitutes a high proportion of its body mass. To investigate whether the giraffe skeleton is affected by its anatomy and biology, giraffe bone density and morphology were compared with those of African buffalo Syncerus caffer, an artiodactyl of similar mass, more conventional anatomy, a lower vertical growth rate, and different diet. Our results show that except for minor differences the density of giraffe bones is the same as that of buffaloes. Giraffe limb bones have a slightly greater diameter and much thicker walls than equivalent bones in buffaloes. Giraffe cervical vertebrae, unlike those in buffaloes, decrease in mass with cranial distance. We conclude that giraffe biology and anatomy do not affect bone deposition or density. However, other characteristics of their skeletons seem to be adaptations to their unique anatomy.
\end{abstract}

Key words: giraffe, Giraffa camelopardalis, African buffalo, Syncerus caffer, skeleton, bone density, bone morphology

\section{INTRODUCTION}

Neck and leg length in the giraffe is dependant on elongation of each of the seven cervical vertebrae (Slijper, 1946; Mitchell \& Skinner, 2003), and of the metapodial bones more than the proximal leg bones (McMahon, 1975). The length of the metapodials and cervical vertebrae, the mass of the animal and gravity will expose these bones to high loading forces.

McMahon (1973), stating the obvious, observed that all animals must be built strongly enough to stand under their own weight. Strength, for a given mass of an animal with increased length of leg bones and the consequential increase in loading forces, is usually provided by increased cross-sectional area of the bone (CloudsleyThompson, 1976). Thus, the bones of animals of small scale are generally more slender than those of large scale (McMahon, 1973). In giraffes, however, this does not seem to be the case. McMahon (1975), Hamilton (1978) and Geraads (1986) have all shown that giraffe distal limb bones have a smaller diameter (and hence cross-sectional area), and are thus more slender, than predicted.

*All correspondence to: O. L. van Schalkwyk.

E-mail: louis.vanschalkwyk@up.ac.za
An alternative to increased diameter of limb bones for providing strength is increased density. Pauwels (1980), for example, has shown that apposition and resorption of bony material are controlled by the magnitude of the stresses, and that human bones under stress become denser at the point of stress. We have made some preliminary measurements that suggest that this may be so for giraffe limb bones (Mitchell \& Skinner, 2003). A mechanism for compensation for an increase in the length of non-weightbearing bones such as cervical vertebrae is unknown, but giraffe cervical vertebrae density should be relatively lower than those of short-necked animals, in order to minimize the mass of the head and neck.

If differences in density are mechanisms that have evolved in giraffes to provide limb bone strength on the one hand and a light neck on the other, or to optimize calcium and phosphate deposition, they may be compromised by characteristics of giraffe biology. For example, the skeleton of giraffes elongates rapidly, more rapidly than in any other mammal (Hall-Martin, 1975; Dagg \& Foster, 1976). Moreover, their diet on average has a calcium to phosphate ratio (Ca:P) of 7.7: 1 (Pellew, 1984; Mitchell \& Skinner, 2003). This ratio is at a level at which, in cattle Bos taurus, clinical signs of phosphate deficiency, such as pica, occur (McDowell, 1992; Underwood \& Suttle, 1999). A form of pica, osteophagia, 
is a well-documented phenomenon in giraffes (NesbitEvans, 1970; Western, 1971; Wyatt, 1971; Hall-Martin, 1975; Langman, 1978), which suggests that dietary deficiencies could occur in them. If dietary deficiencies are compounded by high growth rate, then bone formation (and hence density) may be compromised by them.

Furthermore, the giraffe skeleton constitutes a greater proportion of its body mass than it does, for example, in cattle. Skeletal mass of cattle is c. $15-20 \%$ of dressed carcass mass (Steen \& Kirkpatrick, 1995; Muldowney, Connolly \& Keane, 2001; Simoes \& Mira, 2002), whereas in mature bull giraffes it is about 24\% (Hall-Martin, Von la Chevallerie \& Skinner, 1977). Thus the absolute amount of calcium and phosphate required for bone deposition in them should be proportionately higher.

To assess whether bone density in giraffes is affected by their anatomy, their rapid increase in height, their skeletal mass, and dietary considerations, a study which compared the density of giraffe neck, limb and other bones with comparable bones of African buffaloes Syncerus caffer is reported. Buffaloes have a body mass similar to that of giraffes (Skinner \& Smithers, 1990), but, relative to giraffes, they have a short neck and limb bones. They are also grazers and thus use food sources with a lower Ca:P ratio of c. 2: 1 (Taylor, 1989; Mitchell \& Skinner, 2003), than do giraffes, which are browsers (Pellew, 1984). The anatomy of limb bones using other possible determinants of bone strength are also compared to establish if the morphology of giraffe and buffalo limb bones differs.

\section{MATERIALS AND METHODS}

\section{Sample collection}

Bones for analyses were collected from carcasses of mature giraffe and buffalo bulls killed by predators and hunting/culling operations in and adjacent to the Kruger National Park, South Africa (Fig. 1). Only bulls older than 6 years were collected (i.e. with all permanent incisors/ canines erupted; Hall-Martin, 1975; Taylor, 1988), but the specific age of each animal was not estimated. Skeletons collected from the field varied in age from death of 1 to 14 days depending on when deaths were reported. No separation of bones according to ecological or geological zones was attempted. During the period of collection (February-September 2003) the quality of grass and browse also changed considerably. The effects (if any) of these potential variables have not been analysed.

Bones were collected from 7 giraffe and 9 buffalo carcasses. One of the giraffe carcasses had been frozen for 2 months and this treatment decreased bone density. These bones were discarded. In addition, some individual bones from other carcasses were damaged by predators or bullets and were also discarded.

The following bones were collected from each carcass: (a) third to fifth cervical vertebrae $(\mathrm{C} 3, \mathrm{C} 4, \mathrm{C} 5)$;

(b) second and third lumbar vertebrae (L2, L3);

(c) proximal arch of the 12th rib (Rib) $( \pm 10 \mathrm{~cm})$;

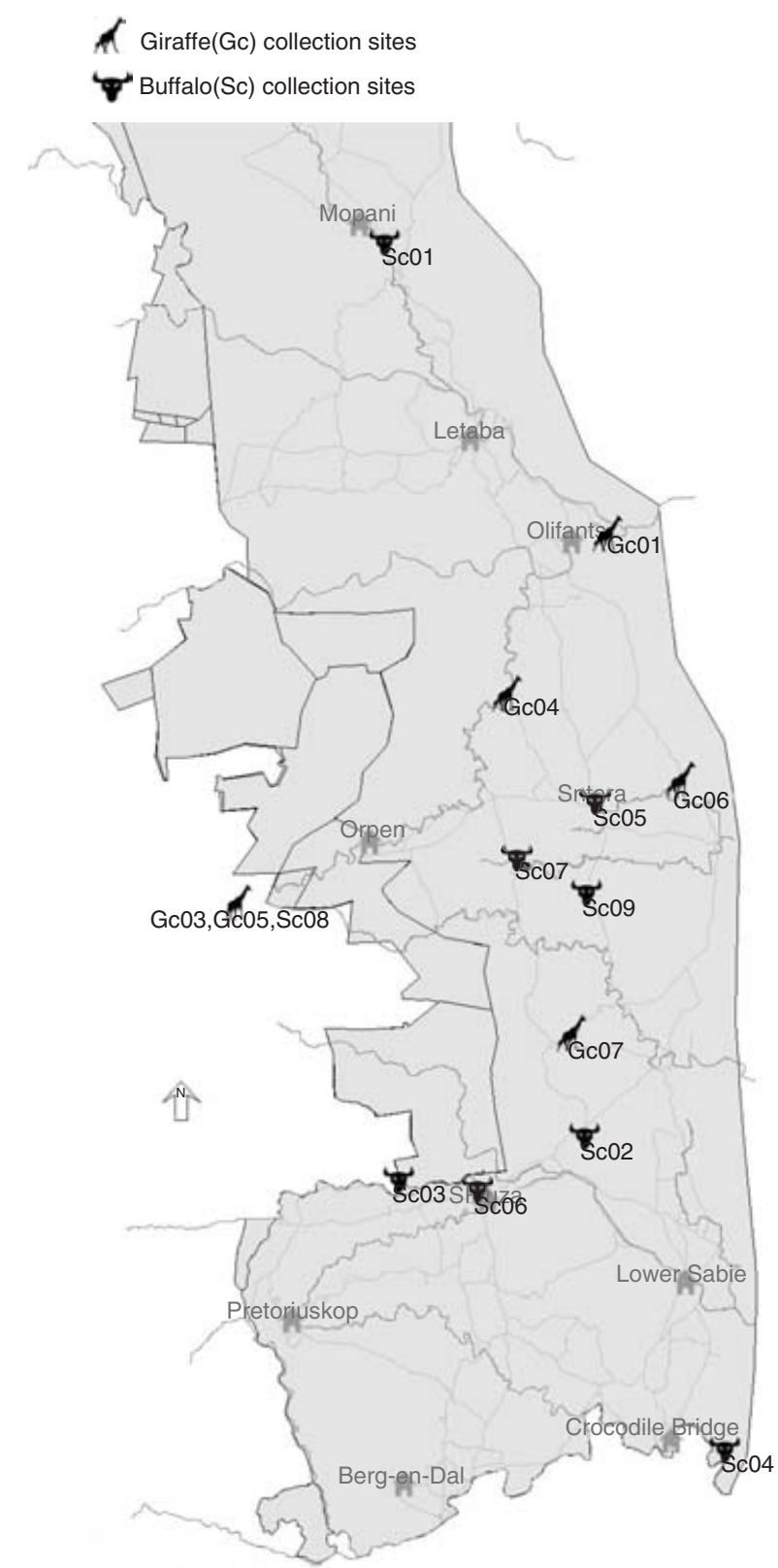

Fig. 1. Map of Kruger National Park showing collection sites.

(d) tuber coxa (Tc);

(e) proximal (Fp) and distal ( $\mathrm{Fd})$ heads, and the mid-shaft (Fs) $( \pm 5-10 \mathrm{~cm})$ of the femur;

(f) radial (rC), intermediate (iC), and ulnar (uC) carpals;

(g) mid-shaft of the metacarpus (Mc) $( \pm 5-10 \mathrm{~cm})$.

\section{Determination of density}

All soft tissue was removed from bones by dissection. The bones were then air-dried to a constant mass, and weighed using a Richter Scale KA-10 (Kubota Ltd, Pretoria, $1 \mathrm{~g}$ accuracy). The volume of each sample was determined by water displacement using two custom-made containers 


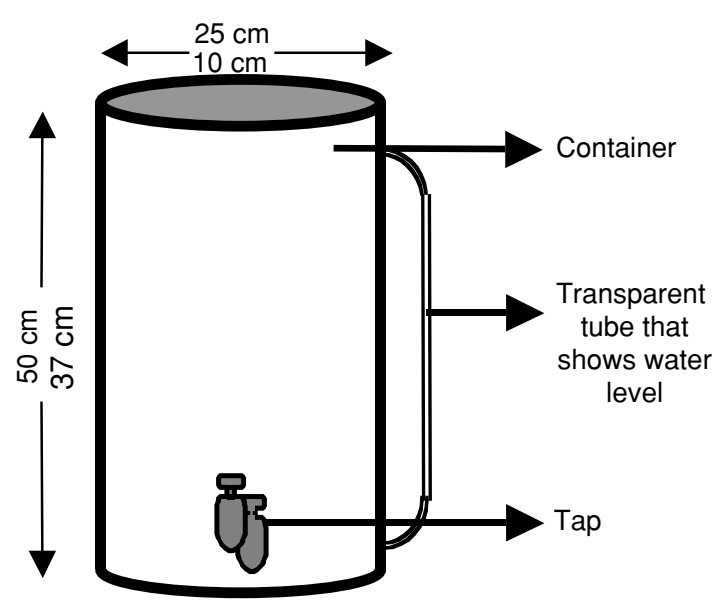

Fig. 2. Basic structure of the two containers used to determine bone volume: dimensions $50 \times 25 \mathrm{~cm}$ and $37 \times 10 \mathrm{~cm}$.

(Fig. 2) of different sizes. One had an inside diameter of $10 \mathrm{~cm}$ and a depth of $37 \mathrm{~cm}$ and was used for determining the volume of small bones, while the bigger one had an inside diameter of $25 \mathrm{~cm}$ and a depth of $50 \mathrm{~cm}$. Each container had a transparent tube connected to it, which showed the internal level of water.

The containers were filled with water $\left(\right.$ at $\pm 22^{\circ} \mathrm{C}$ ) to a set level. This level was marked on the transparent tube. The bone or bone fragment to be sampled was then placed in the container, and submerged. The volume of water displaced caused the water level in the transparent tube to rise. Water was let out of the container via the tap (see Fig. 2) until the water level in the transparent tube returned to its original level. The amount of water drained was collected and weighed. The density of water is $1 \mathrm{~g} / \mathrm{cm}^{3}$, thus the displaced mass of water equals the displaced volume. Absolute density was calculated by dividing bone mass by its volume, and was recorded as $\mathrm{g} / \mathrm{cm}^{3}$. Relative density (\%) was determined by comparing the density of all bones to that of the mid-shaft of the femur (taken to be $100 \%$ ).

\section{Determination of cross-sectional area, diameter and radius}

The femur and metacarpus shafts were transected perpendicular to the shaft at the mid-point of the middle third. The total cross-sectional (TXSA) and marrow crosssectional areas (MXSA) were estimated by drawing their outlines on graph paper and determining surface area $\left(\mathrm{cm}^{3}\right)$ by inspection. Bone area $\left(\mathrm{BA}, \mathrm{cm}^{3}\right)$ at the midshaft was calculated by subtracting marrow area from TXSA. Radius $(\mathrm{cm})$ of the mid-shaft was calculated by assuming that the mid-shaft was cylindrical and using the equation $A=\pi r^{2}$. Similarly bone wall thickness $(\mathrm{cm})$ was calculated by subtracting outer radius from inner (bone marrow) radius. Relationships between TXSA: MXSA, and BA: TXSA (\%) were also determined.

\section{Data analyses}

A 2-tailed Student's $t$-test was used to compare results between species and bones. $P$ values $<0.05$ were regarded as significant.

\section{RESULTS}

\section{Bone density}

Table 1 show the means $( \pm \mathrm{SD})$ for the mass, volume, and density $\left(\mathrm{g} / \mathrm{cm}^{3}\right)$ and Fig. 3 the absolute density $\left(\mathrm{g} / \mathrm{cm}^{3}\right)$ of each of the 14 bones or parts of bones analysed. Table 1 gives the $P$-value for the difference between giraffes and buffaloes for each bone. The figures within each bar in Fig. 3 show the number of bones $(n)$ used to determine each value.

Note that the densest bones that were analysed were the mid-shafts of the femurs. In giraffes, the density of this part of the femur was found to be $1.92 \pm 0.11 \mathrm{~g} / \mathrm{cm}^{3}$ and in buffaloes it was $1.96 \pm 0.05 \mathrm{~g} / \mathrm{cm}^{3}$. Absolute density in

Table 1. Average mass, volume and density of bone samples from Giraffa camelopardalis and Syncerus caffer. P, Significance of difference in density

\begin{tabular}{|c|c|c|c|c|c|c|c|}
\hline \multirow[b]{2}{*}{ Bone sample } & \multicolumn{3}{|l|}{ Giraffe } & \multicolumn{3}{|l|}{ Buffalo } & \multirow[b]{2}{*}{$P$} \\
\hline & Mass (g) & Volume $\left(\mathrm{cm}^{3}\right)$ & Density $\left(\mathrm{g} / \mathrm{cm}^{3}\right)$ & Mass (g) & Volume $\left(\mathrm{cm}^{3}\right)$ & Density $\left(\mathrm{g} / \mathrm{cm}^{3}\right)$ & \\
\hline $\mathrm{C} 3$ & 1795.7 & 1308.0 & 1.4 & 522.4 & 378.3 & 1.4 & 0.863 \\
\hline C4 & 2215.0 & 1686.9 & 1.3 & 560.6 & 402.6 & 1.4 & 0.249 \\
\hline $\mathrm{C} 5$ & 2584.3 & 2011.0 & 1.3 & 567.3 & 415.9 & 1.4 & 0.259 \\
\hline L2 & 503.5 & 383.9 & 1.3 & 344.8 & 251.1 & 1.4 & 0.070 \\
\hline L3 & 521.2 & 390.5 & 1.3 & 374.3 & 268.3 & 1.4 & 0.137 \\
\hline $\mathrm{Fp}$ & 1259.7 & 973.7 & 1.3 & 691.4 & 555.6 & 1.3 & 0.424 \\
\hline Fs & 489.0 & 256.6 & 1.9 & 199.3 & 102.1 & 2.0 & 0.406 \\
\hline $\mathrm{Fd}$ & 2559.5 & 2073.8 & 1.2 & 811.6 & 640.4 & 1.3 & 0.461 \\
\hline $\mathrm{rC}$ & 171.2 & 116.0 & 1.5 & 52.0 & 33.9 & 1.5 & 0.485 \\
\hline $\mathrm{iC}$ & 154.5 & 101.0 & 1.5 & 36.8 & 24.6 & 1.5 & 0.932 \\
\hline $\mathrm{uC}$ & 149.7 & 92.2 & 1.6 & 42.0 & 26.7 & 1.6 & 0.801 \\
\hline Mc & 568.8 & 297.6 & 1.9 & 104.8 & 56.6 & 1.9 & 0.435 \\
\hline Rib & 116.8 & 80.6 & 1.5 & 52.6 & 34.3 & 1.6 & 0.251 \\
\hline $\mathrm{Tc}$ & 218.7 & 182.8 & 1.2 & 143.5 & 133.8 & 1.1 & 0.093 \\
\hline
\end{tabular}




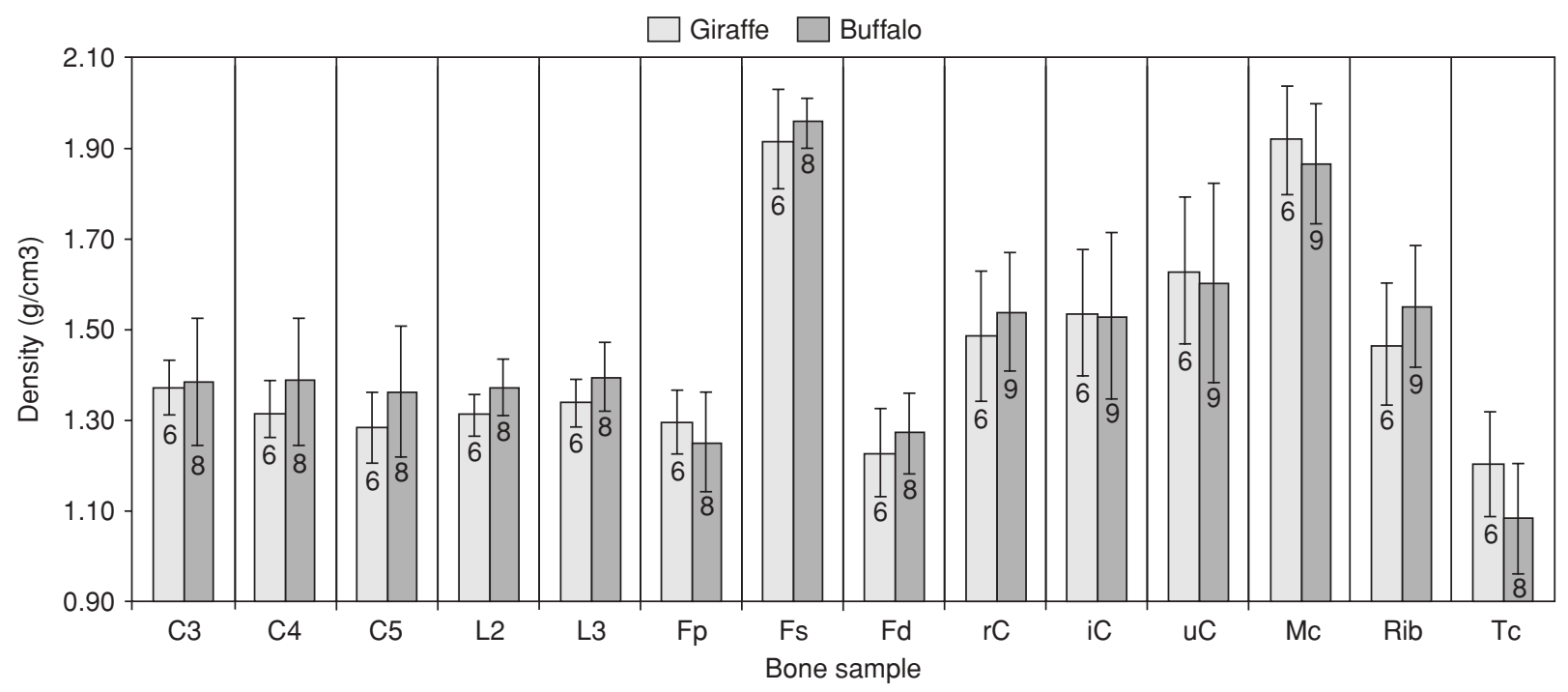

Fig. 3. Absolute bone density of Giraffa camelopardalis and Syncerus caffer.

Table 2. Significant differences between bone density in giraffes Giraffa camelopardalis. NS, Not significant; *, $P<0.05$; **, $P<0.01 ; * * *, P<0.001$

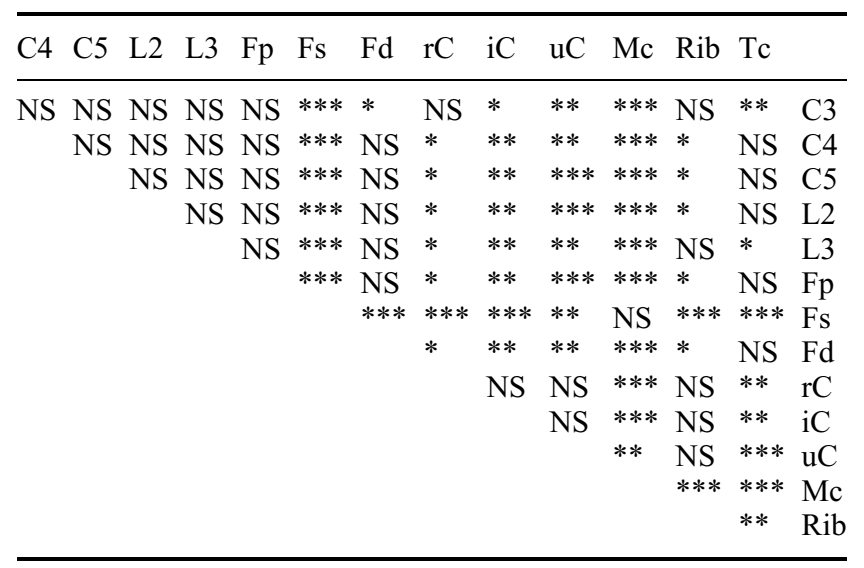

these species was not significantly different $(P>0.05)$. The mid-shaft of the metacarpal bones was the next densest bone averaging $1.92 \pm 0.12 \mathrm{~g} / \mathrm{cm}^{3}$ in giraffes and $1.87 \pm 0.13 \mathrm{~g} / \mathrm{cm}^{3}$ in buffaloes. These densities likewise were not significantly different between the two species and were not significantly different to the density of the mid-shaft of the femurs. Both the femurs and the metacarpals had significantly $(P<0.01)$ higher densities than any of the other bones analysed.

A summary of all the densities and a comparison between giraffes and buffaloes is shown in Tables $2 \& 3$. These tables show that the variation in density is complex. In giraffes for example the hierarchy of densities is: $\mathrm{Mc}>\mathrm{Fs} \gg \mathrm{uC}>\mathrm{iC}>\mathrm{rC}>\mathrm{Rib}>\mathrm{C} 3>\mathrm{L} 3>\mathrm{C} 4>\mathrm{L} 2>$ $\mathrm{Fp}>\mathrm{C} 5>\mathrm{Fd}>\mathrm{Tc}$ where $\gg$ corresponds to a significant change in density. In buffaloes the hierarchy is: Fs $>$ $\mathrm{Mc} \gg \mathrm{uC}>\mathrm{Rib}>\mathrm{rC}>\mathrm{iC}>\mathrm{L} 3>\mathrm{C} 4>\mathrm{C} 3>\mathrm{L} 2>\mathrm{C} 5$ $>\mathrm{Fd}>\mathrm{Fp} \gg \mathrm{Tc}$, which is different in several respects.
Table 3. Significant differences between bone density in buffaloes Syncerus caffer. NS, Not significant; *, $P<0.05$; **, $P<0.01$; ***, $P<0.001$

\begin{tabular}{|c|c|c|c|c|c|c|c|c|c|c|c|c|c|}
\hline $\mathrm{C} 4$ & $\mathrm{C} 5$ & L2 & L3 & $\mathrm{Fp}$ & Fs & $\mathrm{Fd}$ & $\mathrm{rC}$ & $\mathrm{iC}$ & $\mathrm{uC}$ & $\mathrm{Mc}$ & $\mathrm{Rib}$ & Tc & \\
\hline NS & $\begin{array}{l}\text { NS } \\
\text { NS }\end{array}$ & $\begin{array}{l}\mathrm{NS} \\
\mathrm{NS} \\
\mathrm{NS}\end{array}$ & $\begin{array}{l}\text { NS } \\
\text { NS } \\
\text { NS } \\
\text { NS }\end{array}$ & $\begin{array}{l}\text { NS } \\
* \\
\text { NS } \\
* \\
* *\end{array}$ & $\begin{array}{l}* * * \\
* * * \\
* * * \\
* * * \\
* * * \\
* * *\end{array}$ & $\begin{array}{l}\mathrm{NS} \\
\mathrm{NS} \\
\mathrm{NS} \\
* \\
* * \\
\mathrm{NS} \\
* * *\end{array}$ & $\begin{array}{l}* \\
* \\
* \\
* * \\
* \\
* * * \\
* * * \\
* * *\end{array}$ & $\begin{array}{l}\mathrm{NS} \\
\mathrm{NS} \\
\mathrm{NS} \\
* \\
\mathrm{NS} \\
* * \\
* * * \\
* * \\
\mathrm{NS}\end{array}$ & $\begin{array}{l}* \\
* \\
* \\
* \\
* \\
* * \\
* * * \\
* * \\
\text { NS } \\
\text { NS }\end{array}$ & $\begin{array}{l}* * * \\
* * * \\
* * * \\
* * * \\
* * * \\
* * * \\
\mathrm{NS} \\
* * * \\
* * * \\
* * * \\
* *\end{array}$ & $\begin{array}{l}* \\
* \\
* \\
* * \\
* \\
* * * \\
* * * \\
* * * \\
\mathrm{NS} \\
\mathrm{NS} \\
\mathrm{NS} \\
* * *\end{array}$ & $\begin{array}{l}* * * \\
* * * \\
* * \\
* * * \\
* * * \\
* \\
* * * \\
* * \\
* * * \\
* * * \\
* * * \\
* * * \\
* * *\end{array}$ & $\begin{array}{l}\text { C3 } \\
\text { C4 } \\
\text { C5 } \\
\text { L2 } \\
\text { L3 } \\
\text { Fp } \\
\text { Fs } \\
\text { Fd } \\
\text { rC } \\
\text { iC } \\
\text { uC } \\
\text { Mc } \\
\text { Rib }\end{array}$ \\
\hline
\end{tabular}

In general the pattern seems to be that the mid-shafts of the femur and metacarpal bones are the densest, followed by the carpal bones and rib, followed by the vertebrae, with the femur heads and the tuber coxae being the least dense.

Figure 4 shows the relative bone density (\%) of each of the 14 bones, using the density of the mid-shaft femur as the reference bone. The figures within each bar show the number of bones $(n)$ used to determine each value. Note that the cervical and lumbar vertebrae are c. $70 \%$ as dense as the femur and metacarpal bones, and are c. $80 \%$ as dense as the carpal bones. Vertebrae in both species are approximately as dense as the proximal and distal heads of the femur. In giraffes, the tuber coxae have a density similar to that of the vertebrae, while in buffaloes it is significantly lower than that of the vertebrae. Figure 4 emphasizes the complex differences in densities mentioned above. 


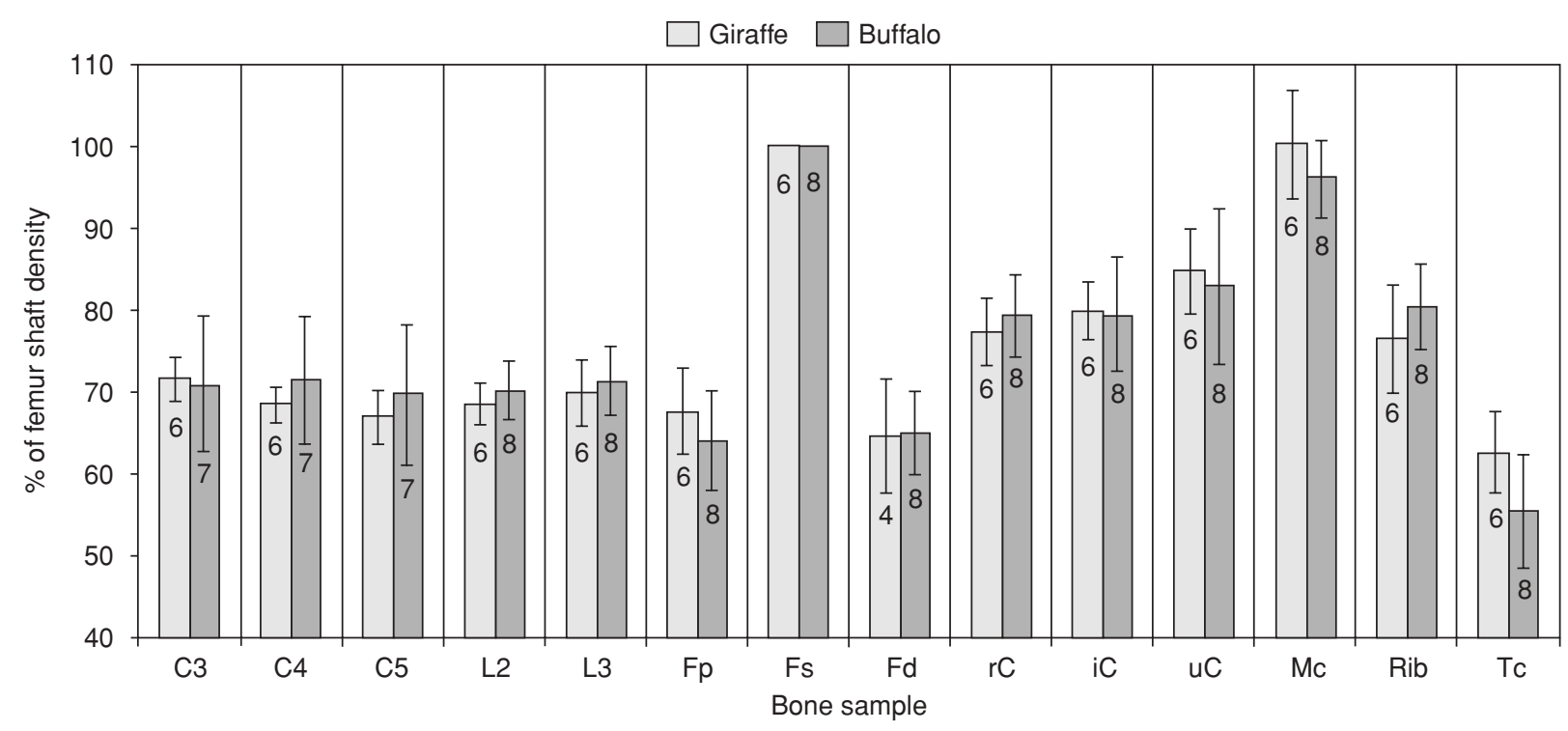

Fig. 4. Relative density of bone samples of Giraffa camelopardalis and Syncerus caffer compared to femur shaft (Fs - taken as $100 \%)$.

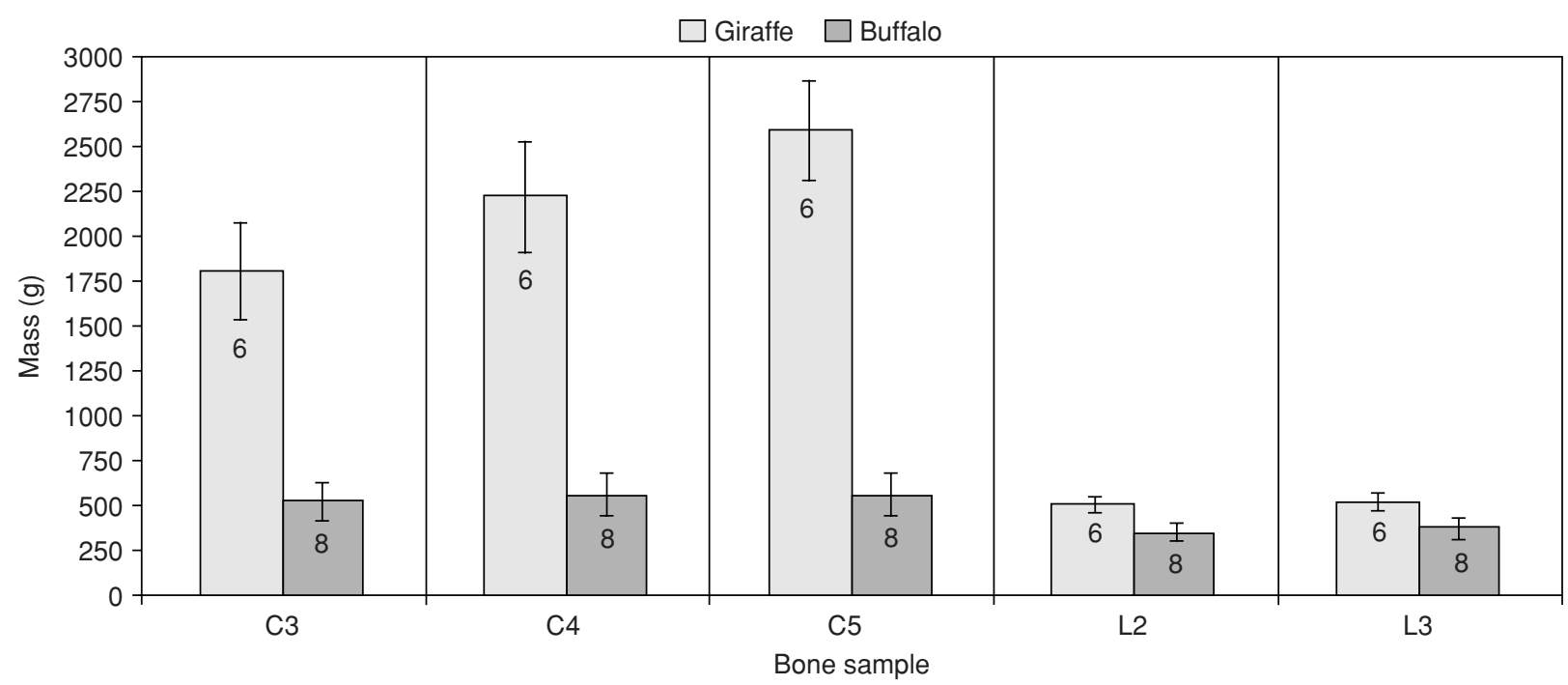

Fig. 5. Mass comparison of cervical and lumbar vertebrae of Giraffa camelopardalis and Syncerus caffer.

Figure 5 shows the mass of the complete cervical and lumbar vertebrae in giraffes and buffaloes. The numerals within each bar show the number of bones $(n)$ used to determine each value.

Note that while their densities are similar, the mass of the cervical vertebrae in giraffes is about four- to fivefold greater than those in buffaloes $(2200 v s 550 \mathrm{~g})$, and fourto fivefold greater than the mass of its lumbar vertebrae $(2200 v s 510 \mathrm{~g})$. In contrast the mass of the buffalo cervical vertebrae is about 1.5 -fold greater than the mass of its lumbar vertebrae $(550 \mathrm{~g} v s 360 \mathrm{~g})$.

Table 4 shows the mean $( \pm$ SD) density of all cervical and lumbar vertebrae and carpal bones grouped together. Although the density of the two lumbar vertebrae in giraffes is significantly lower than those of buffaloes, absolute differences are small. Within a species the density of all vertebrae is the same $(P>0.05)$.
Table 4. Interspecific differences in density in grouped cervical and lumbar vertebrae and carpal bone in Giraffa camelopardalis and Syncerus caffer

\begin{tabular}{lllll}
\hline & Giraffe & & \multicolumn{2}{l}{ Buffalo } \\
\cline { 2 - 2 } & Density $\pm \mathrm{SD}$ & & Density $\pm \mathrm{SD}$ & \\
\hline Cervical vertebrae & $1.3 \pm 0.1$ & & $1.4 \pm 0.1$ & 0.132 \\
Lumbar vertebrae & $1.3 \pm 0.1$ & & $1.4 \pm 0.1$ & 0.017 \\
Carpals & $1.6 \pm 0.2$ & & $1.6 \pm 0.2$ & 0.913 \\
\hline
\end{tabular}

\section{Cross-sectional area, diameter and radius}

Tables $5 \& 6$ show various analyses of total cross-sectional area (TXSA), marrow cross-sectional area (MXSA), bone area (BA), bone diameter, bone radius, marrow radius, and wall thickness (WT) in femurs (Fs) and metacarpal 
Table 5. Comparison of interspecific differences in limb bone morphology in Giraffa camelopardalis and Syncerus caffer. NS, Not significant; * $P<0.05$; $^{*}, P<0.01$; ***,$P<0.001$

\begin{tabular}{|c|c|c|c|c|}
\hline & \multirow[b]{2}{*}{ Measurement } & \multirow{2}{*}{$\frac{\text { Giraffe }}{\text { Mean } \pm \text { SD }}$} & \multirow{2}{*}{$\frac{\text { Buffalo }}{\text { Mean } \pm \text { SD }}$} & \multirow[b]{2}{*}{ Significance } \\
\hline & & & & \\
\hline \multirow[t]{9}{*}{ Fs } & Total XS area $\left(\mathrm{cm}^{2}\right)$ & $33.9 \pm 1.6$ & $19.0 \pm 1.8$ & $* * *$ \\
\hline & Marrow XS area $\left(\mathrm{cm}^{3}\right)$ & $9.3 \pm 1.1$ & $6.5 \pm 1.0$ & $* * *$ \\
\hline & Bone area $\left(\mathrm{cm}^{3}\right)$ & $24.6 \pm 1.5$ & $12.5 \pm 1.3$ & $* * *$ \\
\hline & Bone diameter $(\mathrm{cm})$ & $6.6 \pm 0.2$ & $4.9 \pm 0.2$ & $* * *$ \\
\hline & Bone radius $(\mathrm{cm})$ & $3.3 \pm 0.1$ & $2.5 \pm 0.1$ & $* * *$ \\
\hline & Marrow radius $(\mathrm{cm})$ & $1.7 \pm 0.1$ & $1.4 \pm 0.1$ & $* * *$ \\
\hline & Wall thickness (cm) & $1.6 \pm 0.1$ & $1.0 \pm 0.1$ & $* * *$ \\
\hline & TXSA: MXSA & $3.7 \pm 0.5$ & $3.0 \pm 0.3$ & $* * *$ \\
\hline & BA: TXSA (\%) & $72.5 \pm 3.0$ & $66.0 \pm 3.6$ & $* *$ \\
\hline \multirow[t]{9}{*}{$\mathrm{Mc}$} & Total XS area $\left(\mathrm{cm}^{3}\right)$ & $29.0 \pm 1.7$ & $12.2 \pm 1.8$ & $* * *$ \\
\hline & Marrow XS area $\left(\mathrm{cm}^{3}\right)$ & $6.3 \pm 1.6$ & $3.3 \pm 0.8$ & $* * *$ \\
\hline & Bone area $\left(\mathrm{cm}^{3}\right)$ & $22.7 \pm 2.9$ & $8.8 \pm 1.4$ & $* * *$ \\
\hline & Bone diameter $(\mathrm{cm})$ & $6.1 \pm 0.2$ & $3.9 \pm 0.3$ & $* * *$ \\
\hline & Bone radius $(\mathrm{cm})$ & $3.0 \pm 0.1$ & $2.0 \pm 0.1$ & $* * *$ \\
\hline & Marrow radius $(\mathrm{cm})$ & $1.4 \pm 0.1$ & $1.0 \pm 0.1$ & $* * *$ \\
\hline & Wall thickness $(\mathrm{cm})$ & $1.6 \pm 0.2$ & $0.9 \pm 0.1$ & $* * *$ \\
\hline & TXSA: MXSA & $4.9 \pm 1.4$ & $3.8 \pm 0.8$ & NS \\
\hline & BA: TXSA (\%) & $78.4 \pm 6.4$ & $72.7 \pm 5.2$ & NS \\
\hline
\end{tabular}

Table 6. Comparison of intraspecific differences in bone morphology of Giraffa camelopardalis and Syncerus caffer. NS, Not significant; $*, P<0.05$; $^{* *}, P<0.01$; $^{* *}, P<0.001$

\begin{tabular}{|c|c|c|c|c|}
\hline & & $F_{S}$ & $M c$ & \\
\hline & Measurement & Mean \pm SD & Mean \pm SD & Significance \\
\hline \multirow[t]{9}{*}{ Giraffe } & $\operatorname{TXSA}\left(\mathrm{cm}^{2}\right)$ & $33.9 \pm 1.6$ & $29.0 \pm 1.7$ & $* * *$ \\
\hline & $\operatorname{MXSA}\left(\mathrm{cm}^{3}\right)$ & $9.3 \pm 1.1$ & $6.3 \pm 1.6$ & $* *$ \\
\hline & $\mathrm{BA}\left(\mathrm{cm}^{3}\right)$ & $24.6 \pm 1.5$ & $22.7 \pm 2.9$ & NS \\
\hline & Bone diameter $(\mathrm{cm})$ & $6.6 \pm 0.2$ & $6.1 \pm 0.2$ & NS \\
\hline & Bone radius $(\mathrm{cm})$ & $3.3 \pm 0.1$ & $3.0 \pm 0.1$ & $* * *$ \\
\hline & Marrow radius $(\mathrm{cm})$ & $1.7 \pm 0.1$ & $1.4 \pm 0.1$ & NS \\
\hline & Wall thickness $(\mathrm{cm})$ & $1.6 \pm 0.1$ & $1.6 \pm 0.2$ & NS \\
\hline & TXSA: MXSA & $3.7 \pm 0.5$ & $4.9 \pm 1.4$ & NS \\
\hline & BA: TXSA (\%) & $72.5 \pm 3.0$ & $78.4 \pm 6.4$ & NS \\
\hline \multirow[t]{9}{*}{ Buffalo } & $\operatorname{TXSA}\left(\mathrm{cm}^{2}\right)$ & $19.0 \pm 1.8$ & $12.2 \pm 1.8$ & $* * *$ \\
\hline & $\operatorname{MXSA}\left(\mathrm{cm}^{3}\right)$ & $6.5 \pm 1.0$ & $3.3 \pm 0.8$ & $* * *$ \\
\hline & $\mathrm{BA}\left(\mathrm{cm}^{3}\right)$ & $12.5 \pm 1.3$ & $8.8 \pm 1.4$ & $* * *$ \\
\hline & Bone diameter $(\mathrm{cm})$ & $4.9 \pm 0.2$ & $3.9 \pm 0.3$ & $* * *$ \\
\hline & Bone radius $(\mathrm{cm})$ & $2.5 \pm 0.1$ & $2.0 \pm 0.1$ & $* * *$ \\
\hline & Marrow radius $(\mathrm{cm})$ & $1.4 \pm 0.1$ & $1.0 \pm 0.1$ & $* * *$ \\
\hline & Wall thickness $(\mathrm{cm})$ & $1.0 \pm 0.1$ & $0.9 \pm 0.1$ & NS \\
\hline & TXSA: MXSA & $3.0 \pm 0.3$ & $3.8 \pm 0.8$ & * \\
\hline & BA: TXSA (\%) & $66.0 \pm 3.6$ & $72.7 \pm 5.2$ & ** \\
\hline
\end{tabular}

bones $(\mathrm{Mc})$. Table 5 compares these measurements between species, while Table 6 compares femurs (Fs) with metacarpal bones $(\mathrm{Mc})$.

Figure 6 depicts these results assuming the bones to be cylindrical. Although the femur cross-sectional shape was close to cylindrical, the metacarpal shape, which was anteriorly cylindrical, had a posterior concavity that is more marked in giraffes than in buffaloes. Figures $7 \& 8$ illustrate these differences.

Table 5 shows that the femurs and metacarpals of giraffes have a greater TXSA, with a relatively small
MXSA (27\% of TXSA), and therefore have significantly $(P<0.001)$ thicker walls (WT), than do those of buffaloes. Table 6 shows that giraffe and buffalo femurs have a TXSA greater than their metacarpal TXSA, and the marrow cavities of femurs are bigger than those in metacarpal bones. In giraffes, the bone areas of femurs and metacarpal bones are not significantly different but in buffalo, the BA of femurs is significantly greater than metacarpal BA. The net effect of these differences is that WT of both femurs and metacarpals, although greater in giraffes than in buffaloes, within each species it is similar in both bones. 

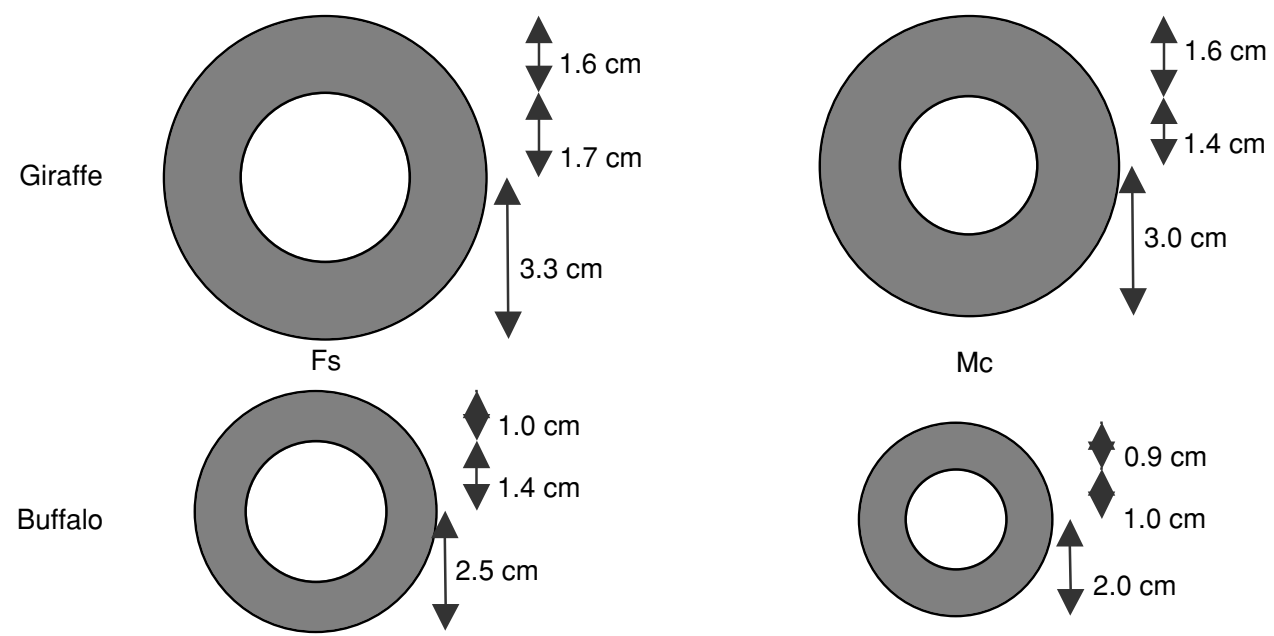

Fig. 6. Graphic representation (cylindrical) of bone cross-sectional areas of Giraffa camelopardalis and Syncerus caffer.

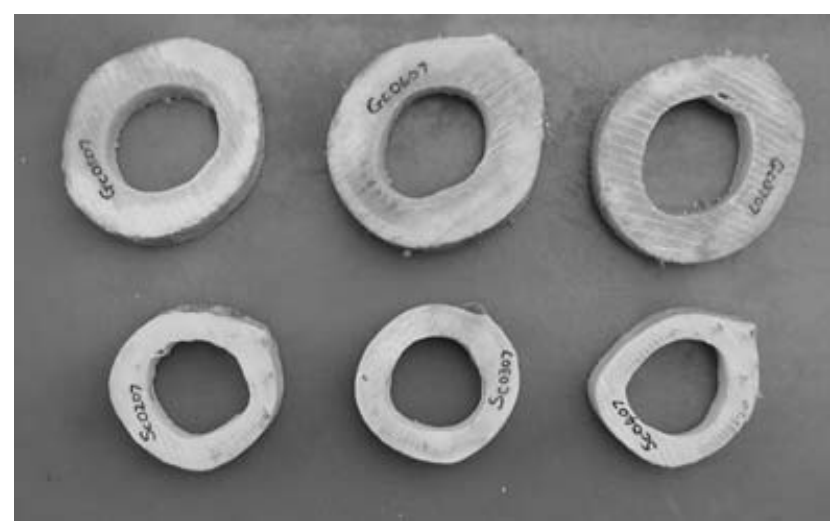

Fig. 7. Cross-sectional samples showing the similarity in shape between giraffe Giraffa camelopardalis (top row) and buffalo Syncerus caffer (bottom row) femurs.

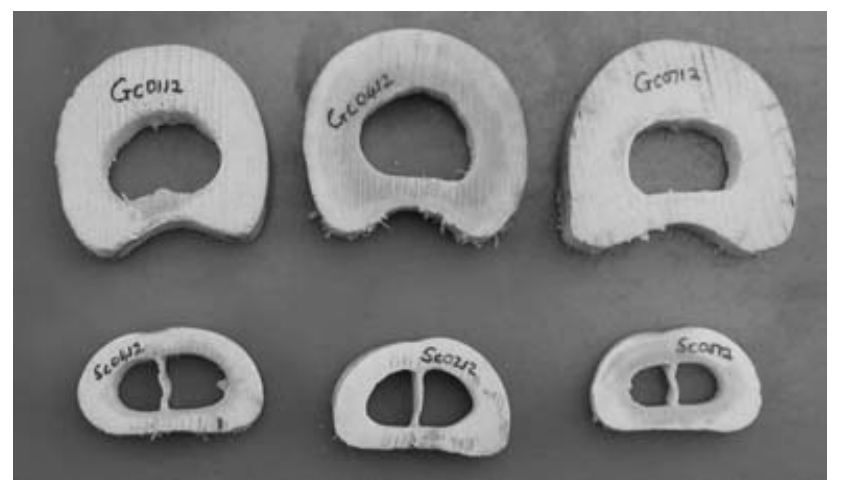

Fig. 8. Cross-sectional samples showing the difference in shape between giraffe Giraffa camelopardalis (top row) and buffalo Syncerus caffer (bottom row) metacarpals.

\section{DISCUSSION}

In our previous study (Mitchell \& Skinner, 2003) we concluded that the relatively low density of cervical vertebrae in giraffes and the relatively high density of their limb bones were unique adaptations to their anatomy. The current study set out to investigate whether these findings are unique to giraffes and whether the rate of vertical growth of giraffes, their anatomy, skeletal mass, and mineral content of their browse affect the density of their bones.

With respect to density our results show that none of these ideas are supported. Except for a small difference in lumbar vertebrae density, no differences were found between giraffe and buffalo densities for any of the bones analysed. This finding is consistent with the idea that bone density of giraffes is not affected by their anatomy or diet. In addition, although the precise ages of the animals from which our skeletons were obtained could not be determined, the absence of any differences in density suggests that the high growth rate of giraffes does not affect their bone density, at least once they have reached maturity. Thus, we can conclude that the density of the giraffe skeleton is not unique, is similar to that of another large herbivore of similar mass and is not affected by the factors that intuitively suggest that it should be unique.

How is giraffe limb bone strength achieved if increased bone density and TXSA are not mechanisms? One mechanism is that the limb bones are much straighter than they are in other artiodactyls and are therefore subjected to lower loading forces. Biewener (1983) measured curvatures (the distance that the mid-shaft deviates from a line joining the centre of the two articulating surfaces) for 11 artiodactyls ranging from hippos Hippopotamus amphibius to dik-diks Madoqua kirkii. He found that the giraffe femur mid-shaft deviated by $1.49 \mathrm{~mm}$ compared to an average of $7.3 \pm 4.2 \mathrm{~mm}$ for the 10 other species. The curvature of the giraffe radius was $5.44 \mathrm{~mm}$ compared to $9.5 \pm 2.7 \mathrm{~mm}$ for the other species.

Our results suggest additional mechanisms. Both the femur and metacarpus in giraffes have diameters that are greater than equivalent bones in buffaloes $(6.6 v \mathrm{~s} 4.9 \mathrm{~cm}$ for femurs, and $6.1 v s 3.9 \mathrm{~cm}$ for metacarpals). However, changes in length should be mirrored by proportional changes in diameter (Alexander, 1977; Alexander et al., 1979; Biewener, 1983). Thus, for a bone that is two 
to three times longer in giraffes than in buffaloes, the diameter should be two to three times greater, but they are not. Giraffe bone diameters, although significantly greater than those in buffaloes, are only $c .1-2 \mathrm{~cm}$ greater. This result confirms the 'slender' nature of giraffe bones. On the other hand, the wall thickness of giraffe bones is significantly greater than it is in buffaloes because marrow cross-sectional area and thus the marrow radius of giraffe bones is much smaller (total marrow volume, $\pi \mathrm{r}^{2} \cdot \mathrm{h}$, is not likely to be smaller in giraffes, however). While femur radius is $0.9 \mathrm{~cm}$ greater in giraffes than in buffaloes, only $0.3 \mathrm{~cm}$ of this increase occurred in marrow radius (Fig. 6). Likewise, the radial increase of the giraffe metacarpals is $1.0 \mathrm{~cm}$ of which only $0.4 \mathrm{~cm}$ is a marrow radius increase. Thus, the necessary strength for giraffe limb bones seems to come not from density, but from a small increase in diameter, almost all of which is bone.

If this is the case, then the ratio of marrow cavity diameter to outside diameter $(k)$ of giraffe limb bones should fall within the general limits defined by Alexander (1982) and Pauwels (1980) for optimal bone strength and economy. They found that for optimal strength and economy of a tubular bone $k$ should lie in the range 0.4 0.7 and ideally should be 0.63 . Alexander (1982) found the ratio in buffalo femurs to be 0.54 , while in this study it was 0.58 in buffalo and 0.52 in giraffes. Our ratios for metacarpal bones were 0.52 and 0.46 in buffaloes and giraffes, respectively.

Nevertheless, our results do show that limb bones are, for example, far denser than vertebrae. These relative differences support the idea that weight-bearing bones are denser than others, and that the strength of limb bones is partly dependent on increased density and not only on cross-sectional area, diameter, wall thickness, or $k$. Another contributing factor may be the shape of the bones. The mechanical consequences of the geometrical shape of the limb cross-sections, especially of giraffe metacarpals were not measured, but the shape together with the angle that the femurs and metacarpals subtend to the vertical, might also provide a mechanical advantage in long, slender bones.

The density of the proximal and distal heads of the femur is similar, but is significantly less dense than is shaft density. This finding confirms those of Benzie et al. (1955, 1959) and Brain (1981), and presumably relates to the spongy nature of the heads compared to the dense bone of the shaft. Vertebrae have a density similar to that of the femur heads and this finding supports our observation that the vertebrae have the same spongy, trabecular type of structure that is found in the femur heads. This type of bone structure is well known to facilitate remodelling.

Low density of the cervical vertebrae possibly reflects both lower loading forces and a greater requirement for remodelling. An advantage of a low density of the cervical vertebrae is that the mass of the neck will be lower than if the bones had the same density as, for example, long bones. In giraffes, one estimate of neck and head weight is $250 \mathrm{~kg}$ (Hall-Martin et al., 1977). If cervical vertebrae had the same density as long bones this weight could increase significantly. Our results show though that the absolute mass of giraffe cervical vertebrae is significantly higher than that of buffaloes, but the difference in mass of the lumbar vertebrae is much less between the two species. The high giraffe cervical mass is a result of their elongation (they have a volume four- to fivefold that of buffalo vertebrae) and occurs despite an absence of bony insertion sites for muscles and ligaments (Lankester, 1908; Solounias, 1999). This result is paradoxical. It seems that a prerequisite for neck elongation should be a relative reduction in neck mass. If gaining access to nutrients is one evolutionary pressure for neck elongation in giraffes (albeit highly unlikely; see Mitchell \& Skinner, 2003), then a light and manoeuvrable neck might have utility. A heavy neck with bones of equal density but greater mass than that of buffaloes suggests that, discounting access to nutrients as a prime purpose of the neck, the giraffe neck has to withstand significant forces such as those that might be expected during 'necking' behaviour (Coe, 1967), and/or that it serves to counterbalance the body during galloping (Dagg \& Foster, 1976). On the other hand, as Fig. 5 shows, giraffe cervical vertebrae mass seems to decrease from proximal to distal while that of buffalo vertebrae does not. The decrease in mass (and volume, as density stays constant) with increase in cranial distance in the giraffe means first, that the mass of its head and neck is supported mainly at the base and secondly that the cranial extremity will be comparatively light and more manoeuvrable than if there was no gradation, as is the case in buffaloes. Thus, the differential densities and other morphological features found in our study could have a biological significance, and may be economical of calcium and phosphate acquisition.

In summary, these results indicate that, despite the unique anatomy of the giraffe, its high vertical growth rate, the high proportion of its body mass that is skeleton, and exposure to an adverse dietary Ca:P ratio, its skeleton is not unique at least with respect to bone density. Its bones have the same density as those of buffaloes, which have a very different anatomy, source of nutrients and a slower vertical growth rate. On the other hand, giraffe cervical vertebrae mass decreases towards the head and its limb bones seem to have significantly thicker walls and are straighter than they are in other artiodactyls. These characteristics may be unique and may provide an explanation for how they support an elongated neck and how their long slender limbs support a large mass. In addition, their limb bones (and those of buffaloes) are denser than other bones, which suggest that density does contribute to bone strength. Our results also provide valuable primary data regarding bone density in both species.

\section{Acknowledgements}

The authors thank the following for assistance in locating and collecting carcasses and samples: Messrs At Dekker and Schalk van Dyk and the rest of the personnel at the State Veterinary Services office, Kruger National Park; personnel of the SANParks Game Capture office, Skukuza and SANParks field rangers; researchers of the 
TB buffalo project in Satara; and Mr Sam Liversidge from Sandringham Private Nature Reserve. Dr Hector Dott is thanked for his advice with statistical analyses of data. OLvS was the recipient of the Blundell and Maberly Memorial Scholarships.

\section{REFERENCES}

Alexander, R. McN. (1977). Allometry of the limbs of antelopes (Bovidae). J. Zool. (Lond.) 183: 125-146.

Alexander, R. McN. (1982). Optima for animals. London: Edward Arnold.

Alexander, R. McN., Jayes, A. S., Maloij, G. M. O. \& Wathuta, E. M. (1979). Alometry of the limb bones of mammals from shrews (Sorex) to elephants (Loxodonta). J. Zool. (Lond.) 189: 305-314.

Benzie, D., Boyne, A. W., Dalgarno, A. C., Duckworth, J., Hill, R. \& Walker, D. M. (1955). Studies of the skeleton of the sheep. Part I: The effect of dietary calcium during pregnancy and lactation on individual bones. J. agric. Sci. (Camb.) 46: 425-439.

Benzie, D., Boyne, A. W., Dalgarno, A. C., Duckworth, J. \& Hill, R. (1959). Studies of the skeleton of the sheep. Part III: The relationship between phosphorus intake and resorption and repair of the skeleton in pregnancy and lactation. J. Dairy Sci. 52: $1-12$.

Biewener, A. A. (1983). Allometry of quadrepedal locomotion: the scaling of duty factor, bone curvature and limb orientation to body size. J. exp. Biol. 105: 147-171.

Brain, C. K. (1981). The hunters or the hunted? An introduction to African cave taphonomy. Chicago: University of Chicago Press.

Cloudsley-Thompson, J. L. (1976). Terrestrial environments. In Environmental physiology of animals: 98. Bligh, J., CloudsleyThompson, J. L. \& Macdonald, A. G. (Eds). Oxford: Blackwell Scientific.

Coe, M. J. (1967). 'Necking' behaviour in the giraffe. J. Zool. (Lond.) 151: 312-320.

Dagg, A. I. \& Foster, J. B. (1976). The giraffe-its biology, behaviour, and ecology. New York: Van Nostrand Reinhold.

Geraads, D. (1986). Remarques sur la systématique et la phylogénie des Giraffidae (Artiodactyla, Mammalia). Geobios 19: 465477.

Hall-Martin, A. J. (1975). Studies on the biology and productivity of the giraffe Giraffa camelopardalis. DSc thesis, University of Pretoria.

Hall-Martin, A. J., Von la Chevallerie, M. \& Skinner, J. D. (1977). Carcass composition of the giraffe Giraffa camelopardalis giraffa. S. Afr. J. Anim. Sci. 7: 55-64.

Hamilton, W. R. (1978). Fossil giraffes from the Miocene of Africa and a revision of the phylogeny of the Giraffoidea. Philos. Trans. R. Soc. Lond. B Biol. Sci. 283: 165-229.
Langman, V. A. (1978). Giraffe pica behaviour and pathology as indicators of nutritional stress. J. Wildl. Manage. 42: 141-147.

Lankester, E. R. (1908). On certain points in the structure of the cervical vertebrae of the okapi and the giraffe. Proc. zool. Soc. Lond. 1908: 320-334.

McDowell, L. R. (1992). Minerals in animal and human nutrition. San Diego: Academic Press.

McMahon, T. A. (1973). Size and shape in biology. Science 179 1201-1204.

McMahon, T. A. (1975). Allometry and biomechanics: limb bones in adult ungulates. Am. Nat. 109: 547-563.

Mitchell, G. \& Skinner, J. D. (2003). On the origin, phylogeny, and evolution of giraffe (Giraffa camelopardalis). Trans. R. Soc. S. Afr. 58: 51-73.

Muldowney, D., Connolly, J. \& Keane, M. G. (2001). Compositional data analysis in the study of carcass composition of beef cattle. Livest. Prod. Sci. 67: 241-251.

Nesbit Evans, E. M. (1970). The reaction of a group of Rothchild's giraffe to a new environment. E. Afr. Wildl. J. 8: 53-62.

Pauwels, F. (1980). Biomechanics of the locomotor apparatus: contributions on the functional anatomy of the locomotor apparatus. Berlin: Springer.

Pellew, R. A. (1984). The feeding ecology of a selective browser, the giraffe (Giraffa camelopardalis tippelskirchi). J. Zool. (Lond.) 202: $57-81$

Simoes, J. A. \& Mira, J. F. F. (2002). Age, empty body weight and carcass composition at the same proportion of total carcass fat in Portuguese cattle breeds. Livest. Prod. Sci. 74: 159-164.

Skinner, J. D. \& Smithers R. H. N. (1990). The mammals of the Southern African sub region. 2nd edn. Pretoria: University of Pretoria.

Slijper, E. J. (1946). Comparative biological-anatomical investigation on the vertebral column and spinal musculature of mammals. Verh. K. Ned. Akad. Wet. Afd. Nat. 42: 1-128.

Solounias, N. (1999). The remarkable anatomy of the giraffe's neck. J. Zool. (Lond.) 247: 257-268.

Steen, R. W. J. \& Kilpatrick, D. J. (1995). Effects of plane of nutrition and slaughter weight on the carcass composition of serially slaughtered bulls, steers and heifers of three breed crosses. Livest. Prod. Sci. 43: 205-213.

Taylor, R. D. (1988). Age determination of the African buffalo Syncerus caffer (Sparmann) in Zimbabwe. Afr. J. Ecol. 26: 207220.

Taylor, R. D. (1989). Buffalo and their food resources: the exploitation of Kariba Lakeshore pastures. Symp. zool. Soc. London No. 61: 51-71.

Underwood, E. J. \& Suttle, N. F. (1999). The mineral nutrition of livestock. Penicuik: CABI.

Western, D. (1971). Giraffe chewing a Grant's gazelle carcass. E. Afr. Wildl. J. 9: 156-157.

Wyatt, J. R. (1971). Osteophagia in Masai giraffe. E. Afr. Wildl. J. 9: 157. 